\title{
The experience and reactions reported by family caregivers of vegetative patients: Qualitative Content Analysis
}

\author{
Research Article
}

\section{Hossein Shamsi Gooshki ${ }^{1}$, Seyyed Hassan Abedian Kalkhoran ${ }^{2 *}$, Seyyed Mohammad Mahdi Ahmadi ${ }^{2}$, Alireza Jalali Farahani ${ }^{3}$, Norouz Mahmoudi ${ }^{4,5}$}

1. PhD Student, Department of Jurisprudence and Principles of Islamic Law, Qom Branch, Islamic Azad University, Qom, Iran

2. Assistant Professor, Department of Jurisprudence and Principles of Islamic Law, Qom Branch, Islamic Azad University, Qom, Iran

3. Professor, Department of Anesthesiology, Faculty of Medicine, Baqiyatallah University of Medical Sciences, Tehran, Iran

4. Ph.D Student, Student Research Committee, Department of Environmental Health Engineering, School of Public Health, Iran University of Medical Sciences, Tehran, Iran

5. Medicine, Quran and Hadith Research Center, Baqiyatallah University of Medical Sciences, Tehran, Iran

\begin{abstract}
Background and objective: vegetative life occurs after serious and widespread damage of brain cortex and deep coma and because of the certain conditions, the responsibility of care for these patients is on their family after discharging from the hospital which influences the physical and mental health of caregivers. The aim of this study is explaining the patient care process for vegetative patients. Methodology: this descriptive-analytical study was conducted by qualitative method in June 2018 in Tehran. Participants of the study were 8 individuals who were selected based on the purposive sampling. Data were collected by deep and unstructured interviews and observation until data saturation and emergence of the main themes in the face-to-face form. Data were analyzed by content analysis. Findings: the results of the data analysis regarding the challenges of the vegetative patients' caregiver indicated 5 main themes and 15 sub-themes as the research axes. The main themes include internal conflict, family reaction, communication with patient, family relationships and difficulty of care. Conclusion: family caregivers of vegetative patients experience various challenges from conflict to problems in the relations and difficulty in care. The results of this study can be considered in the planning care and treatment of patients before, during and after discharge by top policy-makers and managers, middle managers and nursing managers in determining educational, care and therapeutic needs of patients and families of these patients.
\end{abstract}

Keywords: Vegetative patients, care providers, experience of family, qualitative content analysis .

\section{Introduction}

Vegetative state is one of the consciousness level disorders that occurs after serious and widespread damage of brain cortex and deep coma caused by a brain traumatic or non-traumatic accident $(1,2)$. In this state, the brain cortex has destroyed totally and only the brain stem is alive $(3,4)$. Patients are in vegetative state, they have the growth and development capability but their movements are involuntary; they lack mental and cognitive function as well as thinking ability(5). In this condition, the patient is not conscious, cannot understand or interact with other people, their cognitive function and analysis capability is lost; they are not aware of their surroundings; they cannot speak and understand what other people say; they also lack the ability of systematic behavior and response to external

*Corresponding Author:

\section{Seyyed Hassan Abedian Kalkhoran}

Assistant Professor, Department of Jurisprudence and

Principles of Islamic Law,

Qom Branch, Islamic Azad University,

Qom, Iran

E-mail: $\underline{\text { mhabed41@gmail.com }}$ stimulants. They may stimulate in response to external simulants and show automatic reactions like opening eyes after painful stimulation but these movements are not purposive; the automatic functions of body (sleep cycle, awakening, breathing, blood pressure, heart beat) exist (6-8). The caregivers are responsible for the wellbeing and quality of vegetative patients and providing respectful and humane services for vegetative patients is of special importance because they are alive humans $(9$, 10). Although their conditions has defected their selfcare and they need a dependent care and compensatory care system(11). Intensive cares and recent advancements in the science and technology increased the number of these patients by long-term survival (10 to 40 years), although most of the vegetative patients die in the past $(5,12-14)$. Providing the care for vegetative patients, due to increasing their lifetime, has many difficulties for family caregivers. They need continuous medical and nursing care because of their certain conditions, even when their medical condition is stable (15-17). Among their needs are preserving airway, skin health, mouth and teeth health, protection against falling, eye health, preserving liquid balance, meeting nutritional needs, and providing sensory stimulants(18). Therefore, suitable decisions are required about 
medicines, dehydration, nutrition, transmission and replacement(19). Caregivers are under all types of mental disorders in this condition, including anxiety, stress and depression which overshadows the care quality of patients(20-22). Providing care for these patients is very important and different such that in Taiwan, the care is provided for these patients in nursing centers of special hospital wards(23). In France, the care is provided in elderly ward, elderly house, rehabilitation centers, physical care centers or regional hospitals(24). In some countries, including Iran, due to the long-term nature of disease, patients discharge from hospital after their conditions became stable and the care continues in the home(11). Providing care for these patients in the home is very difficult and stressful due to different reasons like continuous and careful care and nursing, time, emotional experiences and conflicts (25), concern about the suffering of patient(19), huge care costs(26) and the stress caused by treatment failure(27).

Various studies have been conducted about the caregivers of vegetative patients. For example, in a study by Guarnerio et al. on the condition of vegetative patients' caregivers, problems in attachment, negligence or maltreatment in childhood, deep relationship with the individual, traumatic nature of the accident and young age of caregivers were disorder predictor variables in these caregivers(7). In a research by Chiambretto et al. (2001), the caregivers of these patients stated that fulltime care has isolated them from other people such that they have no time to visit their friend, go to interesting sites, participate in out of home activities, study, and watch TV(20). In another study by Moretta et al. about the care provided for vegetative patients, it was found that this condition has led to the psychological distress and high sorrow of the caregivers(28). Regarding the importance of special condition of these patients, the need for intensive and full-time care and its effects on the caregivers, this study was conducted to explain the experiences and reactions reported by caregivers of vegetative patients.

\section{Materials and Methods}

This study was conducted in 2018 in Tehran with qualitative content analysis to discover the consequences experienced by caregivers of vegetative patients. This approach can be used when the theory and research about the study subject are scarce(29).

\section{Participants and samples}

Participants of this study were selected by using purposive sampling method. Those subjects were hired who can provide the best description and increase our understanding from the study phenomenon. The number of participants and sample size is not determined before gathering date due to the qualitative nature of this study. The number of participants in the study was determined based on the collected data. When interview with caregivers provided no more new information for us, this is data saturation point. In this study, the address of patients were found by asking from health personnel of patients, especially those who provide care in the homes, because there is no center for vegetative patients and not registering their address in their files in hospital. Therefore, sampling was done based on the addresses found for these patients. The inclusion criterion was direct intervention of home caregivers in providing service for vegetative patients for at least three months. The exclusion criterion was unwillingness to participate in the research process and subjects were excluded from the study if they were not willing to participate. Participants in this study were eight people including three mothers, two spouses, one sister and two brothers. Participants had required diversity in terms of kinship with vegetative patient, marital status, age, gender, living place, education and care duration. The damages caused vegetative state were traumatic and nontraumatic. In the traumatic group, in four cases, vegetative state was caused by car accident and one was for falling from the height during work. In nontraumatic group, one state was caused by brain stroke and two cases by syncope.

\section{Data collection}

This research was a qualitative content analysis in which 8 caregivers of vegetative patients were selected by purposive sampling and semi-structured and face-toface interviews were conducted for data collection. We conducted interviews to provide hypotheses and present valuable descriptive information about this phenomenon and allowed the caregivers to speak about their experiences about the care of the patients. In sum, 8 unstructured and deep interviews were conducted with the caregivers. The place for interview was the home and care place of patients by the consensus of all caregivers. First, we prepared an initial instruction about the semi-structured interview based on the initial and library studies about the vegetative patients' caregivers. At first and after beginning the interview and introducing, the participants in the research were very eager to talk freely about their experiences. Then, we asked questions to analyze the subjects and purpose of the research. For example, in the interview with home caregivers, they were asked to describe their experiences during caring for patient and daily activities to provide care for patient. They were asked questions about the first hospitalization after brain damage and vegetative state diagnosis, care experience and family relationship. The interview duration was about 35 to 70 minutes.

\section{Data analysis}

After collecting data, the text of all interviews were typed and analyzed using MAXQDA11 software and qualitative content analysis. In this study, interview data were analyzed by using qualitative content analysis.

These steps were 1) preparing for having access to the general understanding of the content in order to achieve a sense of data, 2) labeling, classifying codes and abstracting, 3) extracting themes through comparing classes and determining the relationship between them.

\section{Ethical considerations}

Participation in this research was voluntarily for all individuals with written consent form and being aware of the subject of the study. In the case of families consent for participation in the study, agreements achieved about the time and place of interview.

All caregivers and participants in the study were insured regarding the recording the interview and confidentiality of data. Considering the sensitivity and 
emotional burden of traumatic and non-traumatic accidents in the retelling of experiences by caregivers, they were announced that they can stop the interview or refrain the study when they want. During the interview by the researcher, it was tried to provide a secure and conform atmosphere for the family members by sympathy and required supports.

\section{Research limitations}

Very hard access to vegetative patients and their caregivers, non-accompaniment during the research process as well as unreliability of dialogue and confidentiality of data due to the unfamiliarity with the researcher were among the limitations of this research.

\section{Results}

Participants in this study were 8 subjects including 3 mothers, 2 spouses, 1 sister and 2 brothers. The age of participants was 35 to 58 years old, vegetative patients were 5 men and 3 women who were 28 to 47 years old. Three patients were 1 to 2 years in vegetative state, four patients were 3 to 5 years in vegetative state and 1 patient was more than 5 years in the vegetative state. Care duration of vegetative patients varied between 12 to 75 months. Table 1 indicates the demographic information related to the caregivers and participants in the research (table 1).

Table 1: demographic characteristics of participants and vegetative patients

\begin{tabular}{|c|c|c|c|}
\hline Caregivers & & Vegetative patients & \\
\hline Variable & Quantity & Variable & Quantity \\
\hline Age (year) & $47.75 \pm 7$ & Age (year) & $34.75 \pm 6.71$ \\
\hline Gender & & Gender & \\
\hline Male & $2(25 \%)$ & Male & $5(62.5 \%)$ \\
\hline Female & $6(75 \%)$ & Female & $3(37.5 \%)$ \\
\hline Care duration (year & & Vegetative life duration (year) & \\
\hline Total mean & $3.1 \pm 3.74$ & Total mean & $3.1 \pm 54.83$ \\
\hline$<2$ & $2(25 \%)$ & $<2$ & $1(12.5 \%)$ \\
\hline $2-5$ & $5(62.5 \%)$ & $2-5$ & $6(75 \%)$ \\
\hline$>5$ & $1(12.5 \%)$ & $>5$ & $1(12.5 \%)$ \\
\hline Education & & Education & \\
\hline Under diploma & $1(12.5 \%)$ & Under diploma & $1(12.5 \%)$ \\
\hline Diploma \& associate degree & $4(50 \%)$ & Diploma \& associate degree & $4(50 \%)$ \\
\hline Bachelor \& higher & $3(37.5 \%)$ & Bachelor \& higher & $3(37.5 \%)$ \\
\hline Kinship with patient & & Kinship with caregiver & \\
\hline Mother & $3(37.5 \%)$ & Husband & $2(25 \%)$ \\
\hline Wife & $2(25 \%)$ & Son & $1(12.5 \%)$ \\
\hline Brother & $2(25 \%)$ & Daughter & $2(25 \%)$ \\
\hline \multirow[t]{2}{*}{ Sister } & $1(12.5 \%)$ & Sister & $1(12.5 \%)$ \\
\hline & & Brother & $2(25 \%)$ \\
\hline Occupation & & Occupation before accident & \\
\hline Housewife & $2(25 \%)$ & Housewife & $1(12.5 \%)$ \\
\hline Employee & $2(25 \%)$ & Employee & $3(37.5 \%)$ \\
\hline Retired & $2(25 \%)$ & Student & $2(25 \%)$ \\
\hline Self-employed & $2(25 \%)$ & Self-employed & $2(25 \%)$ \\
\hline Marital status & & Marital status & \\
\hline Married & & Married & \\
\hline Male & $2(25 \%)$ & Male & $3(60 \%)$ \\
\hline Female & $6(75 \%)$ & Female & $2(40 \%)$ \\
\hline Single & & Single & \\
\hline Male & - & Female & $2(66.67 \%)$ \\
\hline \multirow[t]{6}{*}{ Female } & - & Female & $1(33.33 \%)$ \\
\hline & & The cause of accident & \\
\hline & & Car accident & $4(50 \%)$ \\
\hline & & Falling from the height & $1(12.5 \%)$ \\
\hline & & Brain stroke & $1(12.5 \%)$ \\
\hline & & Syncope & $2(25 \%)$ \\
\hline
\end{tabular}


After analyzing the obtained codes, challenges that the caregivers and the families of vegetative patients were involved with them were classified in 5 main themes and 15 subthemes.

1-internal conflict and paradox

1-1- contradiction

1-2- confusion and vagueness

1-3- pessimism \& distrust

2 -family reaction

2-1- feeling anger

2-2- denial and not beleiving

2-3- escaping the reality

2-4- non recovery

3-communication with patient

3-1 understanding disease symptoms

3-2 emotional relationship \& attachment

4-family relationships

4-1 disturbance in relationships

4-2 effective relationship

4-3 isolation

5-difficulty in care

5-1 high costs

5-2 healthcares

5-3 specific cares

\section{1-Internal conflict}

This model was extracted from three themes of contradiction, confusion and vagueness, and finally, pessimism and unreliability. This indicates the intellectual and mental challenges developed in the family after informing vegetative patient life.

\section{1-1 Conflict and contradiction}

All families have conflicts or contradictions about the vegetative state and irreversibility after becoming informed of vegetative state of their patients.

[at the first moment that I visited the doctor, he said us that maybe your spouse return to normal state and sometimes he said the return probability for these patients is very low... I don't know what will happen for him at all, if he recovers or remain as this forever? It is very difficult. I don't know yet whether doctors tried their best to recover him or they refrained... only God knows. Participants number 1].

\section{1-2 Confusion and vagueness}

The other factor of this conflict is observing natural symptoms of a healthy individual in the life of a vegetative patient. Almost all families suffered confusion and ambiguity after becoming aware that their patient is in vegetative state. They considered the natural status and appearance of patient like heartbeat and breathing as ambiguous and confusing, despite being aware of the vegetative state.

[I was totally surprised, confused and tires. It is hard for me to describe it. I don't know to do what due to the anxiety and fear. I was going mad. Doctors and nurses said the recovery probability is weak...perhaps he never recovers, but I saw him, he was breathing, his heart was beating well, he was shaking his hands and feet..., participant number 8].

\section{1-3 Pessimism and distrust}

Another group of families stated that distrust and pessimism about the medical team at the time of encountering the vegetative life as another factor of this conflict. This contradiction has imposed severe mental pressure to families at that time.

[when they told about my husband, I said to myself it is not clear that what doctors and nurses are doing or thinking, I can't accept, I can't believe them at all..., participant number 2].

[I didn't know what vegetative life is. I have never seen such patients. I didn't know what it is at all. But I know that I cannot trust the doctors. They easily make mistakes and then say we tried our best but we can do nothing more. I didn't know to believe what.., participant number 7].

\section{2-Family reaction}

This theme is extracted from four main themes of feeling anger, denying, escaping the reality and nonrecovery. One of the important issues in the reaction of families is the lack of information and required understanding about the vegetative state. Therefore, treatment method and giving information can be effective in the correct decision-making.

\section{2-1 Feeling anger}

Some families immediately react and feel anger toward medical team after the accident in the medical centers due to the lack of information about the vegetative state.

[when doctors said they have no hope and nothing can be done, I was very angry and quarreled with doctors. I think they were not entitled to tell such a thing..., participant number 4].

[he was breathing, his heart was beating, I would like to demolish the hospital, they easily say they can do nothing more..., participant number 3].

\section{2-2 Not believing and denial}

Most families denied strongly the vegetative state of their patient to the last moments and reacted to it.

[although doctors and nurses said that the condition will not change but I said that he is healthier than me and he has no complication, he will recover..., participants number 5].

Some families suffered deny and not-believing due to the sudden nature of the accident and the short time interval between the accident and vegetative state. They strongly rejected and denied this issue.

[by seeing his condition, I could not believe, because before the accidents we were talking about everything..., participant number 1].

[when they told me, I couldn't believe. I couldn't believe doctors. How much time was passed from the accident? Believing was difficult.., participant number 7].

\section{2-3 Escaping the reality}

Some patients, despite being aware of their patient condition, escaped the situations which reflect the condition to not encounter and remember it.

[I was confused since they told his condition to me, I didn't want to believe them, I didn't like to see the doctor at all and listen to them. I usually didn't go to the ward at the morning because doctor was there..., participant number 6]. 
[when I want to talk with my husband about our son in the home, he rapidly changed the issue and make himself busy with other things..., participant number 5]. 2-4 Lack of recovery

Most families, after passing so much time of the vegetative state of the patient, had no hope for recovery because their information increased about the severity of damages.

[at first, I thought doctors are lying and he will recover by care but by passing time I found that I'm wrong and he will remain in this state and will never heal. I should accept this and ask God to grant patience to me,...participant number 8].

\section{3-Relationship with the patient}

This theme is extracted from two themes related to the symptoms of the disease and emotional relationship and attachment.

\section{3-1 Understanding symptoms of the disease}

Some caregivers stated that they need a way to become close to patient to communicate with him. They said that they transfer their presence and feelings through physical contact. They stated that they can diagnose the symptoms because they identified the patient well.

[how can I tell you. He cannot tell where he feels pain or what he wants but I understand that he has pain and what he wants by touching him..., participants number 6].

\section{3-2 Emotional relationship and attachment}

Some caregivers talked about the sever attachment to the patients and its effectiveness in communication with patient.

[when others are near him, he is not calm; perhaps he did not know me, but he feels me and knows that I'm caring him, I transfer this feeling to him with the touch and enjoy..., participant number 8].

[I cannot stop thinking about him, I never leave him alone, I'm so attached to him... I love him...when I'm near him I understand that he is good. He looks at me, and smiles...., participant number 5].

\section{4-Family relationship}

This issue is extracted from three themes of disturbance in relationships, effective relationships and isolation.

\section{4-1 Disturbance in relationships}

Disturbance in family relationship was experienced in some families due to the difficulties and complexities of the conditions. Mental problems, inability, disappointing from healing and looking at a new life in the future usually intensified this disturbance.

[at the beginning, even sometimes after the accident, our relationships were quite disturbed. Everyone suffers in a way, there is no patience, because at the beginning, you are angry, with disturbed mind, you don't know what is happening, what will happen next, it is hard to say..., participant number 3].

[I'm always trying to do what I can for my son to make his situation better, but my husband does not, I tell him speak with your son but he cannot speak with his son, I'm suffering much..., participant number 5]. [my son-in-law sought justifications after the accident, he was impatient, he paid no attention to him, he said there is no hope, she will not recover; finally he left his wife by recommendations of his family and married again..., participant number 8].

\section{4-2 Effective relationships}

Regarding the attitude and treatment of family members for effective communication with the mutual understanding, some caregivers introduced family as the main supporter and pillar in all aspects which indicates the commitment of the family members and parents for effective support of each other and their patients.

[how can I tell, it is very painful, difficult days... but the love of a woman for his husband...perhaps the feeling cannot be expressed but I take care of my husband. My children are very well, they understand me and they help me when I'm tired and give hope to me.., participant number 1].

\section{4-3 Isolation}

Some caregivers stated that full-time care of the patient has isolated them such that they have no time to visit relatives or friends, watch TV, going out and recreation.

[sometimes I say why I cannot go out like others, visit my relatives and friends, why? I'm always involved. My soul is tired. I even cannot watch TV. Our relatives and friends did not visit us because of these conditions ...we are isolated from the society.., participant number 2].

\section{5-Difficulty of care}

This theme is extracted from three themes of high costs, health cares and specific cares.

\section{5-1 High costs of care}

All caregivers and families stated that expensive costs of care, including equipment (consumable and non -consumable), nutrition and therapeutic methods of these patients impose the heavy pressure on these families.

One caregiver said about the expensive consumable and non-consumable equipment:

[you should see that how difficult it is for us, we need many things, we run out of them very soon, antisensitivity tape, serum, suction, tampon; we change tampon several times a day...equipment in the room were very expensive....bed and suction; all costs are very high..., participant number 7].

Most caregivers talked about the high costs of nutrition and therapeutic methods:

[funding is very difficult; when he needs gavage, we should pay high costs, for example, 15 to 30 thousand Tomans per day..., participants number 6].

[do not speak about the cost of treatment...we should pay high cost for a visit or physiotherapy,... participant number?].

\section{5-2 Health cares}

Vegetative patients have special needs for providing healthcare like bathing, changing blankets, clothing, and mouth and teeth health.

Most caregivers stated that they pay special attention to the health of their patients. 
[we pay good attention to his health, we take him to bath on time, change the tampon, brush the teeth..., participant number 2].

\section{5-3 Specific cares}

Many specific cares, like suction, controlling vital symptoms, drug therapy, thoracotomy, liquid therapy, nutrition and care of wound are done by home caregivers for patients.

The opinions of some caregivers about the cares were:

[I'm always aware... sometimes that his breath is short I rapidly suction it.., participant number 4].

[he needs gavage every several hours, it is difficult..., participant number 5].

\section{Discussion}

The results of this study indicated that families experienced various challenges including internal conflict, family reaction, relationship with patient, family relationships and difficulty in care. By comparing these themes, we can say that the experiences and challenges acquired by the families are the result of reflecting different reactions of the families during care of their vegetative patient life. These reactions are made out of their innermost feelings and admitting the vegetative life, despite observing the life symptoms in them

The first model showed that the intellectual and mental challenges of the families after becoming aware of their patients' vegetative life have created internal conflicts and contradictions in families.

Caregivers of vegetative patients suffer conflict and contradiction after becoming aware of vegetative state and irreversibility. They states that this conflict is the result of encountering and interaction with the medial teams and doctors. On the other hand, observing natural symptoms of a healthy individual in the life of a vegetative patient is another cause of the conflict and contradiction. They became confused after becoming aware of the vegetative state of their patient such that they considered the normal condition and appearance of the patients such as heartbeat and breathing as confusing and ambiguous.

Most conflicts occur between professionals and families of these patients. In Netherlands, doctors expect that caregivers did not expect recovery. However, it is shown that some patients live for several decades. The role of family is important(30). Participants in this study stated that distrust and pessimism to medical and care team in encountering the vegetative state diagnosis is another factor of this conflict such that conflict imposes high mental pressure to the family.

In this regard, the results of Span-Sluyter study (2018) considered conflicts as well as feelings and conflicted thoughts as one of the general features in four themes, especially experts and families, such that the main themes were common among the families, nursing team and doctors $(30,31)$.

Second model...

One of the most important issues in the reactions of family is the lack of previous awareness and understanding about the vegetative state. Therefore, the treatment and communication can be effective is the correct decision-making such that families immediately feel anger toward medical team and react after becoming aware of the vegetative state. Some families suffered denial and not believing due to the sudden nature of accident and the short interval between accident and vegetative state and rejected and denied it strongly.

The results of Chiambretto (2001) showed that caregivers of these patients used more coping strategies. They also had undesired family relationships and suffered emotional disturbance during their disease. On the other hand, the death thoughts of patients were accompanies with the anxiety and depression symptoms. The daily life of caregivers was specified with the limited social relationships and internal and external interests(20).

Results of our study showed that some of these families, despite of being aware of the patient condition, escaped it such that not to remind and encounter the condition of the patient. They were not even hopeful for the recovery after passing a long time of vegetative state of patient because they became aware of the severity of damages.

The results of Stern et al. confirms that VS condition can create an emotional paradox for caregivers because they cannot plan a mourning strategy; the patients are not dead, they show some motions and needs more help than the time of hospitalization(22).

In addition, caregivers deny what has happened or have some imaginations about the reality in their mind. This condition of uncertainty leads to mental disorders, insomnia, and losing appetite in them(32).

Third model showed that the communication with the patient is one of the most important issues experienced in the family of vegetative patients. Human is a social creature who shows the feeling through communication. Communication needs transferring information from sender to receiver; therefore, for communication, the sender of message should have a thought, idea or feeling to form a message and transfer it. The undesired communication prevents the recovery and may deprive the patient from the health and life forever. Touching the patient for a moment and commenting about his health increase the peace and hope for recovery and can preserve the spirit of the patient.

In this study, caregivers transferred their feelings through physical contact and presence for nonverbal communication and by understanding the patients. They can diagnose the symptoms of the patient before medical team. This type of communication is effective but increase the intense emotional attachment of caregivers to the patients.

In this regard, in a study by Cipolletta et al.(33) to determine the experience of family caregivers of vegetative patients, some caregivers spoke about the need to communicate with the patients and becoming near to them through physical contact and touch to transfer the feelings and understanding the patient. They also referred to their emotional attachment with their 
patients. Their results were consistent with the results of our study. Therefore, this type of emotional and real relationship with the body of patient and attempt to keep him alive can occur as the result of the caregivers belief that their patient is aware of its surroundings. Therefore, regarding the relationship with patients for higher understanding of the body of vegetative patients, the definition presented by Sartre is useful $(34,35)$.

The fourth model states the family relationships and problems of taking care of vegetative patient in the families including effective communication, disturbance in the relationships and isolation as a result of care. An effective caregiver is always hopeful and gives hope. This hope is not only for remaining alive and continuing the life of patients but is means achieving the meaning and purpose and less suffering. Therefore, suitable relationship of family and its supporting role along with the love and hope in providing care for vegetative patients are basic issues in the effective care of these patients.

In this study, according to some participants, the attitude and treatment of the family members in supporting each other for effective communication and mutual understanding has introduced family as the main supporter in all aspects and indicates the commitment of family members and parents in providing effective support for themselves and their patients.

Some participants in this study stated that the commitment of the family members from each other in each condition, including financial, therapeutic and emotional conditions, introduces the family as the basic supporter in all aspects. These results are similar to the results of Gauler et al.(36).

In this study, the disturbance in the family relationships was experienced by some families due to the effects of difficulties and complexities of the condition. Among these cases, we can refer to the mental problems, depression and anxiety, inability, no hope for recovery and look to a new life in the future.

The results of Noohi et al.(37) study showed that empathy and companionship with friends and relatives of vegetative patients is a facilitator that eliminates the pain and mental suffering of care. Another study(16) indicated that the supporting role of friends is effective in reducing the disorder in the relationships, stress, depression, anxiety and increases the self-confidence of the caregivers.

Another parameter in the family relationships is the isolation of caregivers as the result of their full-time involvement with the difficulties caused by it in the care of vegetative patient. This has caused that caregivers of these patients have no time for recreation, watching TV or visiting friends and relatives.

According to the study by Goodarzi et al.(11) providing various cares for several times per day leads to full involvement of the caregivers and their isolation.

In another study by Buchini et al.(9) the most important cause of problems in the care of patients is the isolation of their caregivers due to the full-time involvement and repetitive cares.

The fifth model is the difficulties caused by care. This is the last part of the results of this study which indicates the high difficulties due to the large volume of care, time-consuming, repetitive and long-term cares which lead to the high costs of healthcare and specific cares. Expensive costs of the care for healthcare and specific cares, including equipment (consumable and non-consumable), nutrition and therapeutic methods of the patients imposed heavy pressure to these families. This can double the role of social supports in support of these patients. The lack of support will lead to the financial problems of these families as the result of long -term care of vegetative state.

In this regard, Noohi et al.(37) stated in a study conducted to understand the social support by the family caregivers of the vegetative patients that a VS patient family needs financial and emotional support to cope the problems related to the care and meeting these needs reduces the problems and stresses of families.

In the study by Crispi and Crisci(38), participants were very unsatisfied with their financial condition and care costs, and described their bad financial quality of life.

According to Liu et al.(39) the severity of patient's condition and the costs lead to the severe mental pressures on the caregivers; therefore, families need the support of family members, relatives, government and healthcare specialists in taking care of these patients.

Results of Giovannetti et al.(16) indicated that long-term care of VS patients imposes high cost to their families.

Other studies $(40,41)$ showed that supporting the families of vegetative patients by different sources is effective to promote their quality of life and reduces the stress of family and improves the physical and mental health of caregivers.

Based on the opinions of participants in this research, the direct costs are cost of consumable and non-consumable equipment, nutrition, therapeutic methods (visit, physiotherapy, and occupational therapy) and indirect costs of unemployment of caregivers and disability of patients.

Based on this, in a study by Pagani et al.(42), the results showed that the direct and indirect costs of taking care from VS patients imposes double pressure on the families and caregivers.

The results of Goodarzi et al. study(11) show that regular healthcare, sensory stimulations as well as specific cares like meeting the nutritional needs and defecation, drug and liquid therapy, intravenous injection, thoracotomy, suction. Wound care, and controlling viral symptoms were done for patients by caregivers each day. Similar cares are provided by professional caregivers in the study of Lavrijsen et al. (43).

\section{Conclusion}

The results of this study showed that caregivers family of vegetative patients experience various problems and challenges in the care of patients such that the family of vegetative patients experience the conflict and paradox to loose relationships and difficulty in taking care. Therefore, it is important to 
pay more attention to the caregivers and the patients under their care. The results of this study can be used in the planning for care and treatment before, during and after discharge by policy-makers and top managers, middle managers and nursing managers in determining the educational, and care needs of patients and their families.

\section{Acknowledgement}

We would like to appreciate the cooperation of all families of vegetative patients who shared their experiences.

\section{References}

1. Kuehlmeyer K, Borasio GD, Jox RJ. How family caregivers' medical and moral assumptions influence decision making for patients in the vegetative state: a qualitative interview study. Journal of Medical Ethics. 2012;38(6):332-7.

2. Vincent JL, Abraham E, Kochanek P, Moore F, Fink M. Textbook of Critical Care. 6th ed. Philadelphia: Elsevier Saunders; 2011.

3. PVS M-STFo. Medical aspects of the persistent vegetative state. New England Journal of Medicine. 1994;330(21):1499-508.

4. Yousefzadeh-Chabok S, Emamhadi MR, Alijani B, Cheragh-Sepehr M, Khodadadi-Hassankiadeh N. Investigation of the relationship between individualsocial characteristics of patients in vegetative state and psychological symptoms in family caregivers. Iranian Journal of Rehabilitation Research in Nursing. 2016;3(3):49-56.

5. Jennett B. Thirty years of the vegetative state: clinical, ethical and legal problems. Progress in brain research. 2005;150:537-43.

6. Goldman L, Schafer AI. Goldman's Cecil Medicine E-Book. 24 ed. USA: Elsevier Health Sciences; 2011.

7. Guarnerio C, Prunas A, Della Fontana I, Chiambretto P. Prevalence and comorbidity of prolonged grief disorder in a sample of caregivers of patients in a vegetative state. Psychiatric quarterly. 2012;83(1):65-73.

8. Longo D, Kasper D, Jameson J, Fauci A, Stephen L, Loscalzo J. Harrison's principles of internal medicine. . 18 ed. New York: Mc Graw Hill; 2012.

9. Buchini S, Quattrin R, Zampieron A. Valuing dignity in patients in a vegetative state on an intensive rehabilitation ward: improvement project. Journal of nursing management. 2014;22(2):140-50.

10. Mirra AF. Social problem solving and psychological distress in caregivers of adults with intellectual disabilities: Drexel University; 2011.

11. Goudarzi F, Abedi HA, Zarea K, Ahmadinejad F. Caring experiences and challenges of families with patients in vegetative state. Journal of Clinical Nursing and Midwifery. 2015;3(4):65-79.

12. Beis J-M, Seyer J-L, Brugerolle B, Le Chapelain L, Thisse M-O, Mainard D, et al. Care protocol for persistent vegetative states (PVS) and minimally conscious state (MSC) in Lorraine: retrospective study over an 18-year period. Annals of physical and rehabilitation medicine. 2009;52(5):374-81.

13. Chiambretto P, Moroni L, Guarnerio C, Bertolotti $\mathrm{G}$, Prigerson HG. Prolonged grief and depression in caregivers of patients in vegetative state. Brain Injury. 2010;24(4):581-8.

14. Cipolletta S, Gius E, Bastianelli A. How the burden of caring for a patient in a vegetative state changes in relation to different coping strategies. Brain injury. 2014;28(1):92-6.

15. Donis J, Kräftner B. The prevalence of patients in a vegetative state and minimally conscious state in nursing homes in Austria. Brain injury. 2011;25 (11):1101-7.

16. Giovannetti A, Leonardi M, Pagani M, Sattin D, Raggi A. Burden of caregivers of patients in $\mathrm{V}$ egetative $\mathrm{S}$ tate and $\mathrm{M}$ inimally $\mathrm{C}$ onscious $\mathrm{S}$ tate. Acta Neurologica Scandinavica. 2013;127(1):10-8.

17. Leonardi M, Sattin D, Giovannetti AM, Pagani M, Strazzer S, Villa F, et al. Functioning and disability of children and adolescents in a vegetative state and a minimally conscious state: identification of ICFCY-relevant categories. International Journal of Rehabilitation Research. 2012;35(4):352-9.

18. Kitzinger J, Kitzinger C. The 'window of opportunity'for death after severe brain injury: family experiences. Sociology of Health \& Illness. 2013;35(7):1095-112.

19. Elvira de la Morena MJ, Cruzado JA. Caregivers of patients with disorders of consciousness: coping and prolonged grief. Acta neurologica Scandinavica. 2013;127(6):413-8.

20. Chiambretto P, Rossi Ferrario S, Zotti AM. Patients in a persistent vegetative state: caregiver attitudes and reactions. Acta Neurol Scand. 2001 Dec;104 (6):364-8.

21. Covinsky KE, Newcomer R, Fox P, Wood J, Sands L, Dane $\mathrm{K}$, et al. Patient and caregiver characteristics associated with depression in caregivers of patients with dementia. Journal of General Internal Medicine banner. 2003;18 (12):1006-14.

22. Stern J, Sazbon L, Becker E, Costeff H. Severe behavioural disturbance in families of patients with prolonged coma. Brain Injury. 1988;2(3):259-62.

23. Lin LC, Hsieh PC, Wu SC. Prevalence and associated factors of pneumonia in patients with vegetative state in Taiwan. Journal of clinical nursing. 2008;17(7):861-8.

24. Saout V, Ombredane MP, Mouillie JM, Marteau C, Mathe JF, Richard I. Patients in a permanent vegetative state or minimally conscious state in the Maine-et-Loire county of France: A cross-sectional, descriptive study. Ann Phys Rehabil Med. 2010;53 (2):96-104.

25. Pagani M, Giovannetti AM, Covelli V, Sattin D, Raggi A, Leonardi M. Physical and mental health, anxiety and depressive symptoms in caregivers of patients in vegetative state and minimally conscious state. Clinical psychology \& psychotherapy. 2014;21(5):420-6. 
26. White-Koning M, Arnaud C, Dickinson HO, Thyen U, Beckung E, Fauconnier J, et al. Determinants of child-parent agreement in quality-of-life reports: a European study of children with cerebral palsy. Pediatrics. 2007;120(4):804-14.

27. Li YH, Xu ZP. Psychological crisis intervention for the family members of patients in a vegetative state. Clinics (Sao Paulo, Brazil). 2012;67(4):341-5.

28. Moretta P, Estraneo A, De Lucia L, Cardinale V, Loreto V, Trojano L. A study of the psychological distress in family caregivers of patients with prolonged disorders of consciousness during inhospital rehabilitation. Clinical rehabilitation. 2014;28(7):717-25.

29. Hsieh H-F, Shannon SE. Three approaches to qualitative content analysis. Qualitative health research. 2005;15(9):1277-88.

30. Span-Sluyter C, Lavrijsen JCM, van Leeuwen E, Koopmans R. Moral dilemmas and conflicts concerning patients in a vegetative state/ unresponsive wakefulness syndrome: shared or nonshared decision making? A qualitative study of the professional perspective in two moral case deliberations. BMC medical ethics. 2018; 22;19 (1): 10 .

31. Moratti S. The Englaro Case: withdrawal of treatment from a patient in a permanent vegetative state in Italy. Cambridge quarterly of healthcare ethics : CQ : the international journal of healthcare ethics committees. 2010;19(3):372-80.

32. Tzidkiahu T, Sazbon L, Solzi P. Characteristic reactions of relatives of post $\square$ coma unawareness patients in the process of adjusting to loss. Brain Injury. 1994;8:159-65.

33. Cipolletta S, Pasi M, Avesani R. Vita tua, mors mea: The experience of family caregivers of patients in a vegetative state. Journal of health psychology. 2016;21(7):1197-206.

34. Cipolletta S. Construing in Action: Experiencing Embodiment. Journal of Constructivist Psychology. 2013;26(4):293-305.
35. Melia K. When the body is past fixing: Caring for bodies, caring for people. Journal of Clinical Nursing and Midwifery. 2013;23:616-22

36. Gaugler JE, Kane RL, Kane RA, Newcomer R. The longitudinal effects of early behavior problems in the dementia caregiving career. Psychology and aging. 2005;20(1):100-16.

37. Noohi E, Peyrovi H, Imani Goghary Z, Kazemi M. Perception of social support among family caregivers of vegetative patients: A qualitative study. Consciousness and cognition. 2016;41:150-8.

38. Crispi F, Crisci C. Patients in persistent vegetative state ... and what of their relatives? Nursing ethics. 2000;7(6):533-5.

39. Liu W, Zhu J, Liu J, Guo Q. Psychological state and needs of family member caregivers for victims of traumatic brain injury: A cross-sectional descriptive study. International Journal of Nursing Sciences. 2015;2(3):231-6.

40. Given BA, Given CW, Kozachik S. Family support in advanced cancer. CA: a cancer journal for clinicians. 2001;51(4):213-31.

41. Romaniello C, Farinelli M, Matera N, Bertoletti E, Pedone V, Northoff G. Anxious attachment style and hopelessness as predictors of burden in caregivers of patients with disorders of consciousness: a pilot study. Brain Injury. 2015;29 (4):466-72.

42. Pagani M, Giovannetti AM, Covelli V, Sattin D, Leonardi M. Caregiving for patients in vegetative and minimally conscious states: perceived burden as a mediator in caregivers' expression of needs and symptoms of depression and anxiety. Journal of clinical psychology in medical settings. 2014;21 (3):214-22.

43. Lavrijsen J, van den Bosch H, Koopmans R, van Weel C, Froeling P. Events and decision-making in the long-term care of Dutch nursing home patients in a vegetative state. Brain Inj. 2005;19(1):67-75. 